\title{
SAÚDE MENTAL NA FORMAÇÃO DO PSICÓLOGO
}

\author{
Maria Helena Melhado Stroili
}

\section{RESUMO}

Este artigo propõe um debate sobre o Campo da Saúde Mental, sua estruturação no Brasil, seus conceitos e postulados . A partir dos dados obtidos em teses, dissertações de mestrado, artigos de periódicos, relatórios oficiais e de associações analisados na tese de doutorado da autora, debate-se a articulação da produção do conhecimento, o pensamento e o movimento no interior do Campo da Saúde Mental e suas implicações na formação do psicólogo, com especial destaque à interdisciplinaridade. Põe também em discussão o conceito de saúde e doença mental. As bases teóricas apoiam-se na teoria de Campo de Pierre Bourdieu e na metodologia da Arqueologia do saber de Michel Foucault .

\section{PALAVRAS-CHAVE}

Saúde mental; Interdisciplinaridade; Formação do psicólogo

\section{MENTAL HEALTH IN THE EDUCATION OF THE PSYCHOLOGIST}

\begin{abstract}
This article intends to propose a debate about the Mental Health Field, its structure in Brazil as well as its concepts and proposals. From data gathered in theses, master degree dissertations, periodical articles, official and association reports which were analyzed for the author's doctoral thesis, the articulation of the production of knowledge, thinking and movement in the interior of the Mental Health Field is debated, and its implications in the education of the psychologist, with special emphasis to interdisciplinarity. It also brings into discussion the concept of mental health and illness. The theoretical background is supported by Pierre Bourdieu's Field Theory, and by Michael Foucalt's methodology of Archaeology of knowledge.
\end{abstract}

\section{KEYWORDS}

Mental health; Interdisciplinarity; Psychologist education 
Saúde Mental é o bem estar psíquico e social que não pode prescindir do físico, que harmoniza o homem com seu meio ambiente físico e social. Não significa apenas a ausência de doença ou enfermidade, mas assegura condições favoráveis à reatividade e elaboração de diferentes eventos, positivos ou negativos da vida do ser humano (I CONFERÊNCIA NACIONAL DE SAÚDE MENTAL, Brasil, 1987).

\section{REVISITANDO O CONCEITO E O CAMPO DA SAÚDE MENTAL}

O conceito de Saúde Mental, emerge dos textos mais recentes, revestido de diferentes roupagens, cuja essência está em busca de autonomização e clarificação do "proprium" constituído pelos conceitos, valores e bens simbólicos desse campo.

Ao se referir à formação de conceitos, Foucault (1987) afirma que quando se busca reconstituir a arquitetura dedutivo-conceitual de eventos complexos como disciplinas ou campos, vemos aparecer um jogo de conceitos que nem sempre se organiza e articula de maneira coerente. Então o autor questiona: "Será preciso abandonar essa dispersão à aparência de sua desordem? ... Não se poderia encontrar uma lei que desse conta da emergência sucessiva ou simultânea de conceitos discordantes? Não se pode encontrar entre eles um sistema de ocorrência que não seja uma sistematicidade lógica? “

Por isso Foucault (1987) postula que antes de se resgatar esses conceitos no discurso, seria necessário descrever a organização do campo de enunciados em que aparecem e circulam. O campo enunciativo compreende o domínio da memória, que reúne enunciados já superados, que não definem mais um corpo de eventos nem sua validade, mas em relação aos quais se estabelecem laços de filiação, gênese, transformação, continuidade e descontinuidade histórica. Com essa análise o autor defende que se pode enfim definir os procedimentos de intervenção que podem ser legitimamente aplicados aos enunciados. O conceito de Saúde Mental não foge à dispersão de formações discursivas abordadas pelo autor nessa análise, por isso, antes mesmo de limitar-se a resgatá-lo historicamente, é necessário que se situe e descreva a organização do campo de enunciados no qual esse conceito figura.

Uma questão “de fundo” poderia ser então formulada: Qual o estatuto epistemológico do campo da Saúde Mental? Isso equivale a questionar quais são os critérios orgânicos que as autoridades elaboraram para a organização da teoria do 
conhecimento na área, abrangendo lógica e crítica. Esses critérios, salvo melhor juízo, emergem dos diversos documentos publicados e analisados na tese de doutorado desta autora (STROILI, 2002) como um conjunto de características qualitativas sinalizadoras do pertencimento ao campo, que abrangem valores éticos, humanos e sociais, valores acadêmicos e intelectuais, e valores políticos e econômicos presentes na realidade. Os defendidos nesse campo podem ser descritos em três grupos:

- os da prática: democratização do acesso e qualidade dos serviços públicos de atenção, respeitada a dignidade e integridade humana e os princípios de cidadania, tanto para os usuários como para os agentes e população em geral:

- os da teoria e da articulação das idéias: interdisciplinaridade e integração de diferentes áreas de conhecimento, e a sistematização e divulgação de saberes, gerando novos e preferencialmente interdisciplinares conhecimentos;

- os das políticas : elaboração e implementação de Políticas Públicas mais justas e menos diferenciadoras, que possam sustentar ações concernentes com os valores acima referidos.

Na evolução do conceito de Saúde Mental tiveram papel marcante a Medicina, em especial a Psiquiatria, a Psicologia e a Sociologia. A Psiquiatria e a Psicologia durante anos orientaram sua atuação no campo da saúde, a partir de uma especialidade do saber psicológico - a clínica, especialmente estimulada pelo desenvolvimento da psicanálise. O desenvolvimento da Psicologia da Saúde, estimulou a atuação Comunitária e Institucional, tanto da Psiquiatria como da Psicologia, e promoveu questionamentos ao pensamento "hegemônico” que apoiava as pesquisas e as práticas psicológicas. Dessa forma, a atuação dos profissionais dessas áreas passou a dar ênfase maior às características sociais da “doença mental”; entretanto, a elaboração de um referencial teórico que servisse de base a essa nova área, não se desenvolveu no mesmo ritmo da intervenção e da prática profissional.

Nesse processo o desenvolvimento da Psicologia no campo da saúde não se alijou dos seus problemas teóricos e epistemológicos, nem dos problemas a partir dos quais essa disciplina se desenvolve, em outros campos de aplicação como por exemplo a Psiquiatria, os quais foram incorporando paulatinamente a questão da saúde como eixo essencial de seu próprio desenvolvimento. 


\section{DOSSIÊ \\ Área temática: Ensino de Psicologia "Diálogos sobre a Docência em Psicologia"}

Apesar das contribuições da Psicologia aplicada à saúde não serem tão recentes, a Psicologia da Saúde, enquanto campo formalmente institucionalizado, data de apenas algumas décadas. São hoje identificadas duas tendências na área: uma que preocupa-se com o desenvolvimento de teorias, métodos e pesquisas, e a outra que se dedica à contribuir para a construção de uma sociedade mais saudável, a partir de uma abordagem comunitária, ou ativista-social, a qual adere a um modelo intervencionista . A supremacia do modelo científico positivista que predominava até então em seu percurso teórico-metodológico, vem sendo historicamente questionado, e a necessidade de superar a hegemonia do modelo biomédico, apresenta-se como o desafio contemporâneo, aperfeiçoando a assistência em saúde pela adoção do pluralismo cultural e a reconstituição das ações dos profissionais de saúde.

\footnotetext{
A divisão do saber psicológico em campos específicos de pesquisa e prática representa uma herança do paradigma positivista, que estabelece em seus princípios dominantes, que o objeto deveria fragmentar-se e simplificar-se para obter a objetividade considerada necessária, de um ponto de vista metodológico, o que parece ter conduzido a um único critério na definição dos campos do saber aplicado: os problemas escolhidos para a definição do espaço de ação profissional (GONZÁLEZ, 1997, p.???).
}

Com esse pensamento González pontua que a ênfase nos dados e resultados sobre o desenvolvimento da teoria, definiu o desenvolvimento da pesquisa e da prática profissional, em especial na Psicologia, de forma atomizadora e empiricista. Nesse sentido realizaram-se muitas pesquisas descritivas, vinculadas à "saúde mental”, sem que se buscasse a construção de uma teoria sobre "saúde" que permitisse transcender sua definição semiológica, em termos de ausência de sintomas. Nessa perspectiva o desenvolvimento de uma construção teórica sobre a saúde, supõe a superação de sua definição em termos de normalidade, equilíbrio ou ausência de sintomas. A corrente sócio-histórica e a psicanalítica da Psicologia contribuíram com o substrato teórico da Psiquiatria e das áreas que tradicionalmente têm atuado com a Saúde Mental, as quais tomam a saúde como um sistema que a caracteriza; o organismo humano, como um processo que expressa a qualidade do desenvolvimento, que tomará como parâmetros os elementos biológicos, tanto quanto os subjetivos e os sociais. 


\section{DOSSIÊ \\ Área temática: Ensino de Psicologia \\ "Diálogos sobre a Docência em Psicologia"}

A Psiquiatria incorporou o discurso preventivista em sua reelaboração no movimento de Reforma, dando origem a duas "correntes Psiquiátricas reformistas"; a Psiquiatria Preventiva e a Psiquiatria Democrática. A primeira tem em Caplan seu principal teórico, o qual a descreve como

corpo de conhecimentos profissionais, teóricos e práticos que podem ser utilizados para planejar e executar, planos destinados a reduzir a incidência de distúrbios mentais de todos os tipos numa comunidade (prevenção primária), a duração de um número significativo daqueles distúrbios que efetivamente ocorrem (prevenção secundária) e a deterioração que poderá resultar desses distúrbios (prevenção terciária) ... O pré-requisito fundamental é porém que os profissionais e serviços atentem não só para o que querem fazer e o que suas habilidades lhes permitem realizar, mas, além disso para o problema comunitário total e para a forma como sua contribuição se ajustará melhor ao esforço geral da comunidade. (CAPLAN, 1980, p. 31).

Esse pensamento amplia a visão predominantemente técnica presente na Psiquiatria, voltando sua intervenção preventiva e de promoção de saúde à comunidade e suas “crises” , propondo a equipe comunitária , com um corpo de profissionais de várias áreas como forma de atender a essa ampliação e complexidade.

A Psiquiatria Democrática tem em Franco Rotelli, Basaglia, e col seus principais representantes. Rotelli (1991) assim a descreve:

(...) baseia-se em alguns pontos de referência essenciais: o primeiro é a crítica a todas as instituições totais e, em particular, ao hospital psiquiátrico...outro ponto é a reflexão a respeito das relações entre técnica e política, entendendo que o trabalho é campo específico e não poderia jamais prescindir da matriz de exclusão social sobre a qual os manicômios foram construídos, sobre a qual a própria psiquiatria se funda... Um dos princípios teóricos deste movimento é aquele que firma que a prática é o que se privilegia , isto é, a transformação concreta das instituições existentes é o laboratório de provas de qualquer análise, reflexão e teorização que se queira fazer. (ROTELLI, 1991, p.84-85 )

Sobre isso Amarante (1998) comenta:

os passos iniciais da desinstitucionalização consistem, pois em desconstruir o paradigma problema-solução, no envolver e mobilizar neste processo os atores sociais envolvidos, inclusive os internos- já não mais sob o critério de desalienação - o que permite descobrir que este não é um problema puramente "tecnicocientífico" mas também normativo, social e ético. (AMARANTE, 1998).

Em relação à “doença mental”, Nunes (1992), lembra que a importância dos aspectos sociais na busca de sua compreensão, toma vulto no Século XX com os 


\section{DOSSIÊ \\ Área temática: Ensino de Psicologia "Diálogos sobre a Docência em Psicologia"}

movimentos da Psiquiatria Social e com o desenvolvimento de estudos sociológicos do “estado de saúde de comunidades ou mesmo estratos da população”.

No que se refere às contribuições da Sociologia no sentido de desvelar o processo Saúde - Doença, no campo da Saúde Mental, os estudos de Nunes (1992), nos quais o autor faz uma revisão crítica da literatura sobre o tema, nos auxiliam nessa leitura por apontar a existência de três grandes grupos temáticos de estudos sociológicos sobre a doença - saúde mental:

- O primeiro grupo propõe-se a investigar a natureza do processo saúde - doença reúne pesquisas sobre os fatores sócio-culturais e agrupa os estudos ecológicos, os de comunidade, os de estratificação social e os de grupos específicos.

- O segundo grupo reúne pesquisas sobre as representações da saúde e da loucura e refazem analiticamente o curso histórico do processo conceitual no qual o representante destacado é Michel Foucault.

- O terceiro grupo desenvolve pesquisas sobre a instituição psiquiátrica, as quais têm contribuído significativamente para o grande desenvolvimento da análise institucional, e desencadeiam um intenso movimento de desinstitucionalização da doença mental.

Essa leitura mostra-se ainda pertinente apesar do transcurso de 10 anos, conforme se apresentam os dados analisados em minha tese de doutorado (STROILI, 2002). No entanto ousamos acrescentar um quarto grupo que poderíamos entender, seria derivado do terceiro referido por aquele autor. Constitui-se dos estudos que discutem as estratégias políticosociais e infraestruturais de organização e articulação das idéias e dos diferentes modelos de atuação dentro do campo da Saúde Mental. Reúnem Pesquisas e Relatos de experiências ou projetos nas temáticas de Gestão Pública, da Construção de Modelos de Atenção e de Assistência à Saúde Mental, da sistematização das discussões e idéias acerca das Bases Ideológicas e Teóricas, e das questões relativas à Formação, Capacitação e Relacionamento Interdisciplinar dos profissionais desse novo campo.

A Sociologia tem ainda emprestado ao campo da Saúde Mental sua metodologia de trabalho, e permitido que se formulem questões críticas à sistematização do conhecimento e à explicitação de lacunas conceituais que estudos calcados em modelos psiquiátricos ou psicológicos têm apresentado. 
A saúde como questão humana e existencial é uma problemática compartilhada indistintamente por todos os segmentos sociais. pois saúde e doença exprimem agora e sempre uma relação que perpassa o corpo individual e social, confrontando com as turbulências do ser humano enquanto ser total. Saúde e doença são fenômenos clínicos e sociológicos vividos culturalmente, porque as formas como a sociedade os experimenta, cristalizam e simbolizam as maneiras pelas quais ela enfrenta o medo da morte, e exorciza seus fantasmas. (MINAYO, 1996).

Com essa afirmação Minayo (1996) sintetiza um pensamento essencial à compreensão do homem em sua relação com a saúde e a doença, e destaca que para todas as pessoas, das diferentes classes sociais, saúde e doença envolvem uma complexa rede de interações entre os aspectos físicos, psicológicos, sociais e ambientais da condição humana e de atribuição de significados. Esse pensamento converge para o que Foucault chamou de “dialética das relações” do indivíduo com seu meio.

O processo de estruturação e desenvolvimento do campo da Saúde Mental no Brasil foi descrito e analisado na tese de doutorado que desenvolvemos (STROILI, 2002) sob a ótica das idéias que o acompanharam, das teorias e práticas geradas em sua dinâmica e das estratégias que compuseram suas lutas concorrenciais para definição e apreensão do capital simbólico no movimento maior de estruturação do campo.

Com base na teoria de campo de Pierre Bourdieu procedemos a essas análises apoiadas nos discursos presentes nos documentos de diferentes naturezas (43 teses de doutorado, 112 dissertações de mestrado, 137 artigos de periódicos científicos, 34 relatórios oficiais, 41 relatórios de associações e eventos) resgatados para esse estudo, que pretendia elucidar as origens, movimento e estruturação do campo da Saúde Mental no Brasil.

Michel Foucault, com seus estudos arqueológicos nos forneceu a metodologia de análise do discurso do material empírico e com sua História da Loucura junto a outros teóricos nos forneceu substrato para a busca de compreensão dos principais conceitos que permeiam esse campo.

Os dados analisados revelaram intenso movimento de articulação das idéias, do pensamento e das práticas no campo, e expõem as rupturas políticas, conceituais e metodológicas, bem como as alternativas de reorganização e reelaboração dos conhecimentos acumulados nesse percurso. Pontuamos uma vez mais a necessidade de organização sistemática dessas informações como estratégia de fortalecimento das lutas 
concorrenciais. As pesquisas desenvolvidas junto aos cursos de Pós-Graduação têm exercido importante papel nesse sentido, porém vislumbra-se a necessidade da capacitação do profissional da assistência, não apenas para exercer suas funções na atenção aos usuários como também enquanto pesquisador de uma realidade à qual tem acesso privilegiado, além do que o desenvolvimento da pesquisa "em serviço" poderia trazer novos conhecimentos e apropriação da cultura e da história dessa realidade, por esses agentes, o que faria substantiva diferença em sua ação e interação com essa população. Nessa perspectiva mais uma vez, a Universidade tem importante papel social, não somente contribuindo com a capacitação básica, como também com a capacitação continuada e com a pesquisa "em serviço". Ao inserir alunos e professores na formação "em serviço" a Universidade pode colaborar para a construção de uma nova história desde que tenha conhecimento e clareza de suas possibilidades e limites, nesse contexto.

As temáticas emergentes dos documentos analisados expuseram avanços e lacunas teóricas e metodológicas do campo, as quais têm contribuido substantivamente para a estruturação do campo. É interessante observar que quando estávamos finalizando esse trabalho tivemos a oportunidade de fazer contato com a programação d a III Conferência Nacional de Saúde Mental programada para ocorrer em dezembro de 2001. As temáticas propostas para debates eram: a reorientação do Modelo Assistencial, Os Recursos Humanos, o Financiamento, o Controle Social e os Direitos, Acessibilidade e Cidadania, parte dos quais foram os mais presentes nas pesquisas e documentos analisados, em especial na década de 90. Isso evidencia quanto as pesquisas e trabalhos acadêmicos podem subsidiar a consolidação deste e de outros campos, numa ação cidadã; por outro lado expõe a possibilidade de através dessa ação, caracterizar-se como fundamental dispositivo de poder e transformação social, o que a coloca na mira dos poderes hegemônicos, e explicitamente exposta às lutas concorrenciais pela apropriação dos bens simbólicos, referidos no pensamento de Bourdieu.

Vale lembrar, uma vez mais, o papel dos órgãos legisladores e das associações referidos anteriormente, os quais parecem exercer função mediadora articulando diferentes campos e dimensões do saber, e função estruturante e sistematizadora com a elaboração de 
sínteses de idéias e princípios que orientam a evolução do campo, em diferentes momentos históricos.

\title{
CONSIDERAÇÕES SOBRE A INTERDISCIPLINARIDADE
}

A interdisciplinaridade tem sido estudada e apontada com freqüência cada vez maior como a perspectiva estratégica para a evolução da estruturação do campo da Saúde Mental e de tantos outros, em nosso momento histórico. O fenômeno da interdisciplinaridade tem sido, segundo Japiassu (1976)

\begin{abstract}
Incessantemente invocado e levado a efeito nos domínios mais variados de pesquisa, de ensino e de realizações técnicas...está muito longe de ser evidente. Por estar ganhando uma extensão considerável, merece ser elucidado, tanto no nível de seus conceitos, de seu domínio de investigação, quanto em sua metodologia própria e ainda incipiente. (JAPIASSU 1976).
\end{abstract}

A elucidação do conceito de Saúde Mental como também do modelo crítico da Epidemiologia Social, que busca a compreensão desse processo, evoca a interdisciplinaridade como articuladora e orientadora das interações conceituais, metodológicas e de investigação (NUNES, 1995). No entanto essa referência não é privilégio da pós-modernidade. Suas origens confundem-se com o ideal grego de cultura, a exemplo do programa Paidéia, que "representa a formação de um homem integral, culto, sábio, filósofo, artista - educação e cultura juntavam-se, porém não formal ou abstratamente.” (NUNES, 1995).

Conceitualmente a interdisciplinaridade é caracterizada por uma gama de disciplinas que interagem desde a simples comunicação de idéias, à integração conceitual, terminologica e proceditudinal, embora cada uma delas preserve suas especificidades. Essa concepção explicita que a interdisciplinaridade supera a integração, embora não prescinda dela, pois pressupõe mudança de postura frente ao objeto de estudo de uma área, exigindo o enfrentamento das convergências e das diversidades, e a capacidade para reportar-se ao referencial da “outra”, o que deve instigar ambas as áreas a produzir a reelaboração de seus conhecimentos internos e específicos, bem como a busca de novos conhecimentos e novas alternativas , o que a coloca como condição para a construção coletiva de conhecimento.A interdisciplinaridade é um “sistema” que caracteriza-se por objetivos múltiplos, orientados 


\section{DOSSIÊ \\ Área temática: Ensino de Psicologia "Diálogos sobre a Docência em Psicologia"}

porém por aspectos convergentes de uma disciplina hierarquicamente superior ou prioritária, em função dos conhecimentos que agrega e que servem de referência para outras disciplinas.Trata-se pois de um sistema de dois níveis hierárquicos , que mantém no primeiro nível a disciplina de maior prestígio que congrega conhecimentos comuns às demais disciplinas que o compõem no segundo nível .

Vasconcelos (1997) ao discutir o conceito de interdisciplinaridade, fazendo-o incidir sobre o campo das práticas em Saúde Mental reporta-se aos manuais de Psiquiatria ou de outras especialidades em Saúde Mental , como a Psicologia, a Psicanálise, a Saúde Pública etc, e pontua que muitas das práticas usuais de colaboração entre profissionais da Saúde Mental acabam sendo “auxiliares”. “A expressão paramédica utilizada para caracterizar essa colaboração é bastante ilustrativa... e inclui a apropriação de forma subordinada às contribuições de outras disciplinas.”

Esse autor prossegue pontuando que a interdisciplinaridade é entendida como estrutural, oportunizando reciprocidade, enriquecimento mútuo, com uma tendência à horizontalização de poder entre os campos implicados. "Exige a identificação de uma problemática comum, com levantamento de uma axiomática teórica e/ou política básica, e de uma plataforma de trabalho conjunto, colocando-se em comum os princípios e os conceitos fundamentais esforçando-se para uma decodificação recíproca da significação, das diferenças e convergências destes conceitos, e desta forma gerando uma fecundação e aprendizagem mútua, que não se efetua por simples adição ou mistura, mas por uma recombinação dos elementos internos.” (p. 26).

É evocada como atitude científica que pode promover uma salutar reorganização do meio científico, a sinalização dos limites e possibilidades impostos por uma dada especialidade científica sobre o conhecimento de problemas complexos daquela área, a ampliação da formação plural dos profissionais, o questionamento de eventual “acomodação” dos cientistas e profissionais fundamentada em uma leitura parcial de fenômenos complexos, a educação continuada dos mesmos, favorecendo a atualização e a contextualização dos conhecimentos práticos e teóricos (JAPIASSU, 1976).

Esse autor pontua ainda que a interdisciplinaridade demanda algumas condições ao seu desenvolvimento: a competência e legitimidade científica das especialidades, o 


\section{DOSSIÊ \\ Área temática: Ensino de Psicologia "Diálogos sobre a Docência em Psicologia"}

reconhecimento da parcialidade e relatividade de uma disciplina e a superação das onipotências, a polarização do trabalho interdisciplinar em pesquisas teóricas e práticas de forma articulada, a identificação e reconhecimento de especificidades disciplinares que não guardam relação de convergência, os métodos e conceitos que não se integram, e o planejamento e sistematização criteriosa buscando a construção de uma metodologia interdisciplinar.

No entanto muitos são os obstáculos que se interpõem ao projeto interdisciplinar lembrado por Vasconcelos (1997) referindo alguns autores que enfatizam a importância das rupturas realizadas pelo chamado pós-modernismo.

Para estes a busca de integração, de instaurar formas de unidade e totalidade em um campo de saber múltiplo, pluralista, heterogêneo e fragmentado, pode significar querer voltar o trem da história e restaurar o espírito modernista, iluminista, de uma unidade já perdida e esgotada, e com riscos de totalitarismo" (VASCONCELOS, 1997, p. 26).

Lembra o autor que no campo da Saúde Mental temos exemplos históricos de tentativas dessa natureza que tiveram sérias implicações psicossociais e políticas, como foi o caso do movimento higienista, que teve início nos estados Unidos, com ampla difusão nos países do ocidente, através do qual “a psiquiatria visava ampliar seu foco, intervindo no espaço social mais amplo, através de medidas diretamente normatizantes, eugênicas e racistas” (COSTA,1981).

Ao reconhecer a complexidade dos fenômenos, a interdisciplinaridade reconhece dialeticamente a necessidade de que olhares diferenciados sejam lançados para um mesmo objeto, e assim, não pode prescindir da especialização. Dessa forma cada área deve continuar a pesquisar e produzir seus novos conhecimentos teóricos e práticos, adotando, no entanto uma “razão comunicativa dialogal”. No entanto alguns teóricos apontam também a necessidade de cautela na interposição de diferentes teorias ao mesmo objeto, no que se refere à preservação do nível de análise dos modelos de interpretação do problema ou do objeto, a que cada ciência ou área deu suporte, e que lhe imprime identidade; da linguagem específica de cada área ou campo e do seu significado histórico -evolutivo que não pode ser interpretado descontextualizadamente, sob pena de comprometer a 
preservação de sua identidade, e da exigência de postulados que dêem conta de todo o campo, para o qual se define em conjunto, possibilitando recortes teóricos menos ambíguos, criticamente inseridos.

Além dos obstáculos epistemológicos, filosóficos e metodológicos, enfrentados pela interdisciplinaridade, a constituição dos saberes enquanto estratégia de poder, descrita por Bourdieu, (1983) nos reporta à necessidade de enfrentar a questão da divisão social do trabalho, posto que cada profissão, foi se inserindo no mercado de trabalho, conquistando espaços gradativamente, sistematizando saberes, e rituais de poder, demonstrando sua eficácia e se legitimando diante da sociedade. A formalização que acompanha esse processo, pelas esferas legislativas e representativo-reivindicatórias sofre forte influência da forma de organização das políticas sociais, econômicas e institucionais, o que pode impedir a interação demandada pela interdisciplinaridade. Some-se a isso a questão da cultura social que tende a assumir um conjunto de valores culturais, simbólicos, e de identidade social específica. Dessa forma a interdisciplinaridade convive com as luzes dos ganhos que poderiam trazer a integração articulada sob sua égide, e as sombras do conjunto de estratégias de saber e poder, de competição intra e intercorporativa e de processos socioculturais que lhe impõem barreiras.

A dificuldade em se produzir conhecimento interdisciplinar não é uma perspectiva, nem prerrogativa exclusiva do campo da Saúde Mental. Esse parece ser o grande desafio posto à ciência do novo século, como postula Japiassu (1976). Sobre isso esse autor pontua que para implementar avanços nessa direção é necessária a sistematização das pesquisas e das práticas do campo de maneira articulada. Como já comentamos anteriormente a articulação das temáticas desenvolvidas na pesquisa no campo tem sido substantivamente maior nos últimos 10 anos. No entanto sua legitimidade parece encontrar resistências ao reconhecimento. Pode-se, no entanto de forma planejada promover o aprimoramento dessa estratégia, ampliando-se as parcerias entre agentes e pesquisadores com diferentes vínculos com instituições sociais, planejando-se a "divisão" de problemas comuns em "pesquisas orbitais” a serem desenvolvidas na ótica de diferentes disciplinas, como recomenda Japiassu. Nesse caso é necessário planejarem-se momentos de análise, nos quais se busquem localizar convergências e divergências entre os dados e conhecimentos 
emergentes das diversas disciplinas. Nesse sentido a Conferência Nacional de Saúde Mental acena como locus privilegiado, pois tem a possibilidade de reunir representações significativas dos agentes do movimento, do pensamento e da teoria no campo.

Quer nos parecer que o desafio desta década, no início do novo século, reside na consolidação das estratégias desenvolvidas nos momentos anteriores e na construção de Modelos teórico-críticos que dêem sustentação às propostas reformistas, superando-se o privilégio da técnica e/ou da prática, as quais fizeram e continuarão fazendo sentido na estruturação do campo, desde que articuladas à dimensão teórico-conceitual, que deverá imprimir significado e autonomia às anteriores.

Abib (1997) discute a definição de “doença mental” metaforicamente, apontando que as analogias com o conceito de “doença física” transferido de um sistema físico, para um objeto de outra natureza como é o mental, "se for adotada acriticamente , reduz a razão prática de sua ação, a qual é fundamentalmente de natureza moral, à razão técnica, que é basicamente de natureza estratégica e instrumental:

\begin{abstract}
a razão prática visa à autonomia moral do ser humano ...A razão técnica é cega quanto a fins; ela não busca conhecer a filosofia social, moral e política de seus procedimentos, estratégias e instrumentos, ela é instrumental e convive sem constrangimentos com uma teologia do bem e do mal. Reduzida e subordinada à razão técnica, a razão prática submerge, e leva consigo a razão teórica.... Que é o esforço de apresentar alternativas de compreensão de um problema” (ABIB, 1997, p. 42-43).
\end{abstract}

Com essa incursão queremos destacar a importância de se buscar a elucidação crítica, porém mais positiva de Saúde Mental, de forma a viabilizar, conforme pontua Abib, seu desenvolvimento “evitando-se assim a forma tradicional de ação que se dá no nível da doença.”.

Esse pensamento soma-se ao de Amarante (1998) quando discute que

a desinstitucionalização está na crítica à idéia de uma resposta exclusivamente técnica para o tratamento dos problemas mentais, ou melhor, a crítica à idéia, por si só ideológica, de que o problema mental seja um problema exclusivamente psiquiátrico... A nova Psiquiatria enquanto instituição da tolerância torna-se apenas um novo momento de uma mesma psiquiatria, que vislumbra uma nova solução técnica específica para o problema da enfermidade mental. Se a violência é rechaçada, e em seu lugar é adotada a tolerância, tal substituição não é suficiente para resolver o problema da enfermidade mental; talvez seja o mesmo, e simplesmente, apenas uma solução social e ideológica (AMARANTE, 1998, p.95). 


\title{
DOSSIÊ \\ Área temática: Ensino de Psicologia "Diálogos sobre a Docência em Psicologia"
}

Finalizando, resgatamos o pensamento de Vasconcelos (1997) que sintetiza com propriedade as questões emergentes no estudo que desenvolvemos.

\begin{abstract}
Como se pode depreender da descrição desse novo paradigma ou estratégia, o campo da Saúde Mental é chamado a refazer-se por inteiro, ampliando o seu foco de abordagem e buscando romper com as delimitações dos saberes tradicionais na área, buscando uma nova recomposição de conhecimentos sustentado sobre um conjunto de rupturas e novas premissas, e que, portanto não seja apenas uma nova somatória ou rearranjo simples dos antigos saberes parcializados. Na minha opinião, não tenho dúvidas de que neste novo paradigma teremos de necessariamente recolocar a questão da interdisciplinaridade, ou mais radicalmente, da transdisciplinaridade. (VASCONCELOS, 1997, p. 23).
\end{abstract}

Considerando as questões pontuadas, e o contexto socioeconômico contemporâneo de perda da visão de totalidade; de tendência à fragmentação e à individualização; de valores imediatistas de consumo cada vez mais prestigiados; de aprofundamento das diferenças sociais, agora ampliadas pela dificuldade de acesso à tecnologia por ricos e pobres com igualdade; e do arrefecimento dos movimentos políticos , da utopia humanista e dos projetos coletivos,facilmente pode-se transformar a escola, desde a Educação Infantil até a Universidade, mesmo no nível Pós -Graduado, em empresa, na qual o consumidor é o aluno e o professor o mercador de "bens" que agradem o freguês. Por isso mais do que nunca a Universidade, como espaço de resistência, e de contestação, e de ampliação do pensamento, da reflexão, do debate e da crítica precisa ser preservada.

Não basta, portanto, que essa instituição forme profissionais da Psicologia bem informados em teorias e técnicas para atuar em Saúde Mental, mas é vital que desperte o aluno e o professor para a importância de seu engajamento social e político, superando a supremacia da burocracia e da reprodução de "rituais didático-pedagógicos" que desconsideram a dimensão ética. e política do pensar e do fazer psicológico.Também é essencial que se reconheça o que postulam Japiassu (1976) e Vasconcelos (1997) pontuando a perspectiva interdisciplinar, como a mais promissora na evolução do conhecimento científico neste momento histórico. O descabido temor da Psicologia de perder sua especificidade e identidade quando se abre à integração com outras áreas do conhecimento pode dissimular o medo e a resistência ao novo, perseverando na adoção de modelos de formação do psicólogo que se sabem ultrapassados, e que se fecham á crítica e 
à ética. Os saberes compartilhados e reeditados na relação crítica com outras áreas do conhecimento, permitem que se aprofunde o conhecimento e o significado da ciência e das tarefas que exercemos na Psicologia, pois a crítica demanda o mergulho nas raízes do conhecimento, delimita compromissos e localiza a concepção de homem e de sociedade que orienta um projeto, seja ele de formação ou de atuação profissional.

\section{REFERÊNCIAS}

ADIB, J. A. D. Saúde mental: esvaziamento de uma trama conceitual. Revista Psicologia em Estudo, v.2 n.1, p. 41-70, 1997.

ALMEIDA FILHO, N. Cultura e psicopatologia. Revisão da literatura epidemiológica Latino-Americana. Jornal Brasileiro de Psiquiatria, v. 34, n.6, p. 357-364, 1985.

AMARANTE, P. Loucos pela vida: a tragetória da reforma psiquiátrica no Brasil. 2. ed. Rio de Janeiro: Fiocruz,1998

BASTIDE, R. Sociologia das doenças mentais. Trad. Ramiro Fonseca. Lisboa: Europa América, 1965.

BASÁGLIA, F. - A psiquiatria alternativa contra o pessimismo da razão, o otimismo da prática. Conferências no Brasil. São Paulo: Ed. Brasil Debates, 1979.

BOURDIEU, P. - A economia das trocas simbólicas. 2. ed. São Paulo: Perspectiva, 1987, p. 99-181.

CAMPOS, F. C. B.; SPINK, M. J. (Org.). Psicologia e saúde: representando práticas. São Paulo: Hucitec, 1992. v.6, Série Saúde Loucura.

CAPLAN, G. Princípios de la psiquiatria preventiva. Buenos Aires: Paidos, 1967.

CARVALHO, A.M.A. Onde estão e o que fazem nossos mestres e doutores? Uma reflexão sobre os critérios de avaliação da pós-graduação. Psicologia Ciência e Profissão, Brasília, ano 19 n.2, p. 54-63. 1999.

CONSELHO REGIONAL DE PSICOLOGIA. Trancar não é tratar: liberdade o melhor remédio. São Paulo, 1997.

CONTINI, M. L. J. Discutindo o conceito de promoção de saúde no trabalho do psicólogo que atua na educação. Psicologia Ciência e Profissão, Brasília, v.20, n.2, p.46-59, 2000. 
FOUCAULT, M. - Doença mental e psicologia. Trad. Lilian R. Shalders. Rio de Janeiro: Tempo Brasileiro 1975. (Coleção Biblioteca Tempo Universitário).

FOUCAULT, M. - A arqueologia do saber. Trad. Luiz Felipe B. Neves, Rio de Janeiro: Forense Universitária, 1987, p. 239, 4 Ed. (Coleção Campo Teórico).

GONZÁLEZ, F.REY - Psicologia Saúde: Desafios atuais in Psicologia e Crítica. Porto Alegre, 1997, v. 10 n.2 p. 275-288.

JAPIASSU, H. Interdisciplinaridade e patologia do saber. Rio de Janeiro, Imago, 1976.

LILAC, S. Literatura latina americana em ciência da saúde. BIREME (Sistema Latino Americano e do Caribe), Brasília, 2001. Disponível em: http://www.bireme.br/php/index.php.

LUZ, M. As instituições médicas no Brasil. Rio de Janeiro: Graal, 1986.

MARÇAL RIBEIRO, P. R. Saúde mental: dimensão histórica e campos de atuação. São Paulo: Ed. Pedagógica Universitária, 1996.

MARSIGLIA, R. G. et al. Saúde mental e cidadania. São Paulo: Hucitec, 1995. (Coleção Saúde em Debate).

MINAYO, M. CECÍLIA, O desafio do conhecimento: pesquisa qualitativa em saúde. 4.ed. São Paulo: Hucitec, 1996.

NUNES, E. D. A questão da interdisciplinaridade no Estudo da Saúde Coletiva e o papel das ciências sociais. In: CANESQUI, A . M. (Org.). Desafios e dilemas das ciências sociais na saúde coletiva. São Paulo: Hucitec, 1995. p. 95-113.

As ciências sociais em saúde e reflexões sobre as origens e a construção de um campo de conhecimento. Saúde e Sociedade, v.1, n.1, p. 59-84, 1992.

PITTA, A. M. Limites e possibilidades de saúde mental em saúde pública. São Paulo: Mineo, 1984.

SPINK, M. J. (Org.). O conhecimento no cotidiano: representações sociais na perspectiva da psicologia social. São Paulo: Ed. Brasiliense, 1993.

STROILI, M.; HELENA M. Saúde mental no Brasil: uma análise da estruturação e do desenvolvimento do campo. 2002. Tese (Doutorado) - Faculdade de Ciências Médicas, Universidade Estadual de Campinas, Campinas, 2002. 
VASCONCELOS, E. M. - Desinstitucionalização e interdisciplinaridade em saúde mental, Cadernos do IPUB, n.7. Rio de Janeiro: UFRJ, 1997 